\title{
Treatment of Lactic Acidosis with
}

\section{Dichloroacetate in Dogs}

\author{
Robert Park and Allen I. Arieff with the technical assistance of \\ William Leach and Virginia C. LaZarowitz, Division of Nephrology, \\ Department of Medicine, Veterans Administration Medical Center; \\ University of California School of Medicine, San Francisco, California 94121
}

A B S T R A C T Lactic acidosis is a clinical condition due to accumulation of $\mathrm{H}^{+}$ions from lactic acid, characterized by blood lactate levels $>5 \mathrm{mM}$ and arterial $\mathrm{pH}<7.25$. In addition to supportive care, treatment usually consists of intravenous $\mathrm{NaHCO}_{3}$, with a resultant mortality $>60 \%$. Dichloroacetate (DCA) is a compound that lowers blood lactate levels under various conditions in both man and laboratory animals. It acts to increase pyruvate oxidation by activation of pyruvate dehydrogenase. We evaluated the effects of DCA in the treatment of two different models of type B experimental lactic acidosis in diabetic dogs: hepatectomy-lactic acidosis and phenformin-lactic acidosis. The metabolic and systemic effects examined included arterial blood $\mathrm{pH}$ and levels of bicarbonate and lactate; the intracellular $\mathrm{pH}(\mathrm{pHi})$ in liver and skeletal muscle; cardiac index, arterial blood pressure and liver blood flow; liver lactate uptake and extrahepatic splanchnic (gut) lactate production; and mortality. Effects of DCA were compared with those of either $\mathrm{NaCl}$ or $\mathrm{NaHCO}_{3}$. The infusion of DCA and $\mathrm{NaHCO}_{3}$, delivered equal amounts of volume and sodium, although the quantity of $\mathrm{NaHCO}_{3}$ infused $(2.5 \mathrm{meq} / \mathrm{kg}$ per $\mathrm{h}$ ) was insufficient to normalize arterial $\mathrm{pH}$.

In phenformin-lactic acidosis, DCA-treated animals had a mortality of $22 \%$, vs. $89 \%$ in those treated with $\mathrm{NaHCO}_{3}$. DCA therapy increased arterial pH and bicarbonate, liver $\mathrm{pHi}$ and cardiac index, with increased

This work was presented in part at the Annual Meeting of American Federation for Clinical Research (AFCR), San Francisco, CA. (1978. Clin. Res. 26: 410a), and at the Annual Meeting, Western Section, AFCR, Carmel, CA. (1979. Clin. Res. 27: 48a.)

Dr. R. Park is a Research Associate of the Veterans Administration.

Address all correspondence to Dr. A. I. Arieff, Veterans Administration Medical Center, San Francisco, CA 94143.

Received for publication 29 December 1981 and in revised form 9 March 1982. liver lactate uptake and a fall in blood lactate. With $\mathrm{NaHCO}_{3}$ therapy, there were decrements of cardiac index and liver $\mathrm{pHi}$, with an increase in venous $\mathrm{pCO}_{2}$ and gut production of lactate.

Dogs with hepatectomy-lactic acidosis were either treated or pretreated with DCA. Treatment with DCA resulted in stabilization of cardiac index, a fall in blood lactate, and $17 \%$ mortality. $\mathrm{NaHCO}_{3}$ was associated with a continuous decline of cardiac index, rise in blood lactate, and $67 \%$ mortality. In dogs pretreated with $\mathrm{NaCl}$, mortality was $33 \%$, but all dogs pretreated with DCA survived. Dogs pretreated with DCA also had lower blood lactate and higher arterial $\mathrm{pH}$ and bicarbonate than did those pretreated with $\mathrm{NaCl}$.

Thus, in either of two models of type B experimental lactic acidosis, treatment with DCA improves cardiac index, arterial $\mathrm{pH}$, bicarbonate and lactate, and liver pHi. The mortality in dogs with type B lactic acidosis was significantly less in DCA-treated animals than in those treated with other modalities.

\section{INTRODUCTION}

Lactic acidosis is a clinical syndrome characterized by metabolic acidosis caused primarily by accumulation of hydrogen ions from lactic acid. In general, patients with this disorder have blood lactate levels $>5 \mathrm{mM}$, bicarbonate levels $<15 \mathrm{mM}$, and arterial $\mathrm{pH}<7.25$ $(1,2)$. The two major forms of lactic acidosis are classified as type A and type B (3). In type A lactic acidosis, there is clear evidence of conditions causing tissue hypoxia, such as shock or hypovolemia; in type $B$, there is no obvious cause for tissue hypoxia. The mortality in patients with lactic acidosis is $>85 \%$ in type $A$ and $50 \%$ in type $B(1,4,5)$. The therapy of lactic acidosis has consisted primarily of intravenous bicarbonate, frequently in excess of $1,000 \mathrm{meq} / \mathrm{d}(1-4)$.

We have recently shown that bicarbonate treatment of animals with experimental phenformin-induced lac- 
tic acidosis decreased cardiac output, increased lactate production by the splanchnic bed, and decreased intracellular $\mathrm{pH}(\mathrm{pHi})^{1}$ in liver and erythrocytes. Furthermore, bicarbonate therapy had no effect on mortality (83\%) when compared with saline treatment (83\%) (6). These results, together with the substantial mortality associated with bicarbonate treatment in patients with lactic acidosis $(2,5)$, suggest that the role of bicarbonate therapy in this disorder should be reevaluated.

Dichloroacetate (DCA) is a compound that lowers blood levels of glucose, triglycerides, and lactate under fasting or diabetic conditions, in both man and laboratory animals (7-10). In muscle, DCA increases the oxidation of pyruvate and other substrates derived from glucose by activation of pyruvate dehydrogenase $(11,12)$, the rate-limiting enzyme complex that regulates the entry of pyruvate into the tricarboxylic acid cycle.

The effect of DCA on blood lactate levels suggests that it might be useful in the treatment of type B lactic acidosis (13). This study was therefore designed to evaluate the systemic and metabolic effects of DCA in two different models of experimental type B lactic acidosis in the dog: phenformin-induced lactic acidosis and hepatectomy-lactic acidosis. Previous studies from this laboratory have shown that in dogs with phenformin-lactic acidosis, there is increased production of lactate by the extrahepatic splanchnic vascular bed (gut), along with impaired liver lactate uptake, low liver $\mathrm{pHi}$, and decreased cardiac output (14). In hepatectomy-lactic acidosis, cardiac output also decreased (15). In this study, we evaluated the effects of DCA on the aforementioned abnormalities.

\section{METHODS}

Animal groups. Studies were carried out in eight groups of adult mongrel dogs of both sexes, mean weight $( \pm$ SD) $23.9 \pm 6.3 \mathrm{~kg}$ fasted for $16 \mathrm{~h}$. The groups of dogs were: $(a)$ control diabetic dogs subjected to $180 \mathrm{~min}$ of general anesthesia; (b) phenformin-lactic acidosis; (c) phenformin-lactic acidosis treated with $\mathrm{NaHCO}_{3} ;(d)$ phenformin-lactic acidosis treated with DCA; $(e)$ hepatectomy-lactic acidosis; $(f)$ hepatectomy-lactic acidosis treated with $\mathrm{NaCl} ;(g)$ hepatectomy-lactic acidosis treated with DCA. Group 8 consisted of 10 dogs with hepatotectomy-lactic acidosis treated with either $\mathrm{NaHCO}_{3}$ (group 8a) or DCA (group 8b). In this group, measurements were made only of cardiac index and arterial $\mathrm{pH}$ and lactate.

Experimental procedures. Diabetes was induced by surgical pancreatectomy (14). Diabetic dogs, plasma glucose at least $17.5 \mathrm{mM}$, were then maintained for 9-20 d on Purina dog chow (Ralston Purina, Co., St. Louis, MO), NPH insulin (5-15 U/d to maintain plasma glucose between 8 and 16

${ }^{1}$ Abbreviations used in this paper: DCA, dichloroacetate; $\mathrm{HA}$, hepatic artery; HPV, hepatic portal vein; HV, hepatic vein; $\mathrm{pHi}$, intracellular $\mathrm{pH}$.
$\mathrm{mM}$ ), oral pancreatic extract (Entozymme, A. H. Robbins, Richmond, VA) (3 pills/d), and vitamin K (Aquamephyton, Merck, Sharp \& Dohme, West Point, PA) (10 mg every other day). $2 \mathrm{~d}$ before the experiments insulin was withdrawn. At experiment time arterial levels of bicarbonate, acetoacetate, and $\beta$-hydroxybutyrate were normal. The animals were anesthetized with pentobarbital $18-20 \mathrm{mg} / \mathrm{kg}$ i.v., intubated, and mechanically ventilated with a Harvard large animal respirator (16) (Harvard Apparatus Co., S. Natick, MA). In all animal groups, arterial $\mathrm{pCO}_{2}$ was adjusted to $\sim 35 \mathrm{~mm} \mathrm{Hg}$ by small adjustments in the tidal volume.

In groups 2,3 , and 4 , the abdomen was opened via a midline abdominal incision, and, when appropriate, polyethylene cannulas were placed in the aorta via the femoral artery, the inferior vena cava via the femoral vein, in the hepatic portal (HPV) vein via a branch of the splenic vein, and in the hepatic vein (HV) via the jugular vein. Both the HPV and hepatic artery (HA) were enclosed via a Statham flowmeter (Gould Statham blood flowmeter, model SP 2202, Gould, Inc., Medical Products Div., Oxnard, CA) cuff that was used to measure hepatic and splanchnic blood flow. A catheter was inserted into the pulmonary artery to measure cardiac output via thermodilution, using a cardiac output computer (No. 601, Instrumentation Laboratories, Inc., Lexington, MA).

Lactic acidosis was induced in groups 2-4 by infusion of phenformin hydrochloride (kindly supplied by Ciba-Geigy Corporation, Ardsley, NY), $7.5 \mathrm{mg} / \mathrm{kg}$ per h for a mean of $210 \mathrm{~min}$ (14). All dogs had arterial lactate levels $>5 \mathrm{mM}, \mathrm{pH}$ $<7.25$, and bicarbonate $<12 \mathrm{mM}$. Dogs in group 2 were killed after the $210 \mathrm{~min}$ of infusion. Dogs in group 3 were then treated with intravenous $8.4 \% \mathrm{NaHCO}_{3}$ infused at a rate of $2.5 \mathrm{meq} / \mathrm{kg}$ per $\mathrm{h}$ for a maximum of $4 \mathrm{~h}$ (mean rate of infusion $=60 \mathrm{meq} / \mathrm{h}$ ). Dogs in group 4 were given DCA in $5.8 \% \mathrm{NaCl}, 50 \mathrm{mg}$ i.v. as a bolus followed by sustained infusion at a rate of $25 \mathrm{mg} / \mathrm{kg}$ per h (mean infusion $=4 \mathrm{meq}$ / h), also for a maximum of $4 \mathrm{~h}$. The rate of infusion of fluid and sodium were the same in groups 3 and 4 . The DCA was administered as the sodium salt. Experiments were terminated either after $4 \mathrm{~h}$ of therapy, or before $4 \mathrm{~h}$ if either mean arterial pressure fell below $60 \mathrm{mmHg}$ or cardiac index fell below $50 \%$ of the pretreatment value. Data in Table I for groups 3 and 4 were obtained at the termination of experiments.

Lactic acidosis was induced in groups $5,6,7$, and 8 via functional hepatectomy produced in the following manner: a polyethylene catheter was inserted into the vena cava via the right femoral vein. Through a midline abdominal incision, the HPV was mobilized for $2-3 \mathrm{~cm}$ caudal to its entry into the liver. The HPV was ligated and then cannulated caudally. The HPV and vena cava catheters were connected with bayonet-style attachments so that HPV flow was completely diverted into the inferior vena cava. The total time required to complete diversion of HPV flow was $<3 \mathrm{~min}$. The HA was then identified and ligated.

Dogs in group 5 were given intravenously $154 \mathrm{mM} \mathrm{NaCl}$, $0.4 \mathrm{meq} / \mathrm{kg}$ per $\mathrm{h}$, beginning at the completion of hepatectomy and continuing for the duration of the experiment, which averaged $201 \pm 31 \mathrm{~min}$. Dogs in group 6 received $\mathrm{NaCl}$ as above, beginning $2 \mathrm{~h}$ before hepatectomy. These animals were studied for a maximum of $4 \mathrm{~h}$ after hepatectomy. Group 7 dogs were pretreated with DCA beginning $2 \mathrm{~h}$ before hepatectomy. The dogs received a continuous infusion of DCA, $300 \mathrm{mg} / \mathrm{kg}$ per h for a maximum of $360 \mathrm{~min}$. Group 8 dogs were given intravenously $\mathrm{NaCl}(0.4 \mathrm{meq} / \mathrm{kg}$ per h$)$ beginning at the time of hepatectomy and continuing for $150 \mathrm{~min}$. They then received either $\mathrm{NaHCO}_{3}$ at a rate of 2.5 
$\mathrm{meq} / \mathrm{kg}$ per h or DCA as a bolus of $50 \mathrm{mg}$ i.v. followed by a continuous infusion of $25 \mathrm{mg} / \mathrm{kg}$ per h (groups $8 \mathrm{a}$ and $8 \mathrm{~b}$ ). The studies continued for a maximum of $390 \mathrm{~min}$. For group 7 and $8 \mathrm{~b}$ dogs, the DCA was administered as the sodium salt following partial neutralization with $\mathrm{NaOH}$ to $\mathrm{pH}$ 6-6.5 The DCA was administered intravenously through an in-line 0.4$\mu \mathrm{m}$ filter (Millipore Corp., Bedford, MA) at a concentration of $7.5-12.5 \mathrm{mg} / \mathrm{ml}$ for group 8 dogs, and $90-150 \mathrm{mg} / \mathrm{ml}$ in group 7 animals. The DCA was disolved in $5.8 \% \mathrm{NaCl}$ and administered such that the rate of total sodium and volume delivery was similar in $\mathrm{NaCl}$ or $\mathrm{NaHCO}_{3}$ vs. DCA-treated dogs (groups 6 vs. 7 and $8 \mathrm{a}$ vs. $8 \mathrm{~b}$ ).

Tissue and blood samples. In all groups, serial studies were made in arterial and $\mathrm{HPV}$ blood of $\mathrm{pH}, \mathrm{pCO}_{2}, \mathrm{pO}_{2}$, bicarbonate, glucose, lactate, and pyruvate. In groups 1,2 , 3 , and 4 , the above were also measured in the $\mathrm{HV}$ and vena cava.

Intracellular $\mathrm{pH}(\mathrm{pHi})$ was measured in both liver and skeletal muscle using ${ }^{14} \mathrm{C}$-labeled 5,5'dimethyloxazolidinedione (DMO, New England Nuclear, Boston, MA) as previously described $(16,17)$.

Serial determinations of cardiac output using thermodilution technique were done in groups $1-5,8 a$, and $8 b$, and serial measurements of HPV flow were done in groups 1-4.

The techniques for measurement in blood of lactate, pyruvate, glucose, $\mathrm{pH}, \mathrm{pCO}_{2}, \mathrm{pO}_{2}$, and bicarbonate have been described $(14,16)$.

Calculations. Data are presented as mean $\pm \mathrm{SE}$. For statistical analysis, the unpaired $t$ test was used with the appropriate control, as indicated in the text. The paired $t$ test was used only where indicated in the text.

In our measurements, the HA blood flow in seven normal dogs subjected to $180 \mathrm{~min}$ of anesthesia was $10.2 \pm 3.9 \mathrm{ml} / \mathrm{kg}$ per min, while that in HPV was $30.6 \pm 6.4 \mathrm{ml} / \mathrm{kg}$ per min. These values were not different after 1,2 , or $3 \mathrm{~h}$ of anesthesia. Thus, HA flow was $25 \%$ of total liver blood flow, a value that agrees closely with published values (18). HA flow was not measured in all studies, and when HPV flow was measured alone, HA flow was assumed to be a constant fraction (25\%) of total liver blood flow. For all subsequent calculations of total liver lactate load and fractional liver lactate uptake, liver blood flow was calculated assuming HPV flow to represent $75 \%$ of total liver blood flow.

The lactate load presented to the liver was calculated as the sum of (HPV lactate) (HPV blood flow) + (HA lactate) (HA blood flow). Fractional hepatic lactate uptake was calculated as lactate extracted by the liver divided by lactate load presented to the liver. Hepatic lactate uptake was calculated as follows: hepatic lactate uptake $=0.75$ (HPV lactate $)+0.25$ (HA lactate $)-($ HV lactate $) \times($ HA + HPV blood flow).

\section{RESULTS}

Controls and dogs with phenformin-lactic acidosis. The values for arterial blood $\mathrm{pH}, \mathrm{pO}_{2}$, bicarbonate, lactate, and $\mathrm{pHi}$ of muscle and liver, are shown in Table I. Compared with control diabetic dogs, those with phenformin-lactic acidosis (phenformin infusion for $210 \mathrm{~min}$ ) had metabolic acidosis $(\mathrm{pH}=7.08 \pm 0.05)$ and hyperlactatemia (lactate $=8.2 \pm 0.7 \mathrm{mM}$ ). The $\mathrm{pH}$, lactate, and bicarbonate were not different from values in groups 3 and 4 before therapy. The cardiac index was $58.3 \pm 9.5 \mathrm{ml} / \mathrm{kg}$ per $\mathrm{min}$, vs. the control of $112 \pm 8.7$ $\mathrm{ml} / \mathrm{kg}$ per $\min (P<0.01)$. The $\mathrm{pHi}$ of liver $(6.81 \pm 0.05)$ was also significantly below the control value (7.08 $\pm 0.04, P<0.01)$.

Dogs with phenformin-lactic acidosis were then treated with either intravenous $\mathrm{NaHCO}_{3}$ (group 3) or DCA (group 4). Before treatment the values for arterial $\mathrm{pH}$, lactate, and bicarbonate were $7.15 \pm 0.03$, $7.0 \pm 0.5 \mathrm{mM}$, and $9.5 \pm 0.5 \mathrm{mM}$ in group 3 , and in group 4 arterial $\mathrm{pH}$ was $7.14 \pm 0.04$, lactate was $8.6 \pm 0.9 \mathrm{mM}$ and bicarbonate was $9.6 \pm 1.6 \mathrm{mM}$. None of the values were significantly different in group 3 vs. group 4 dogs. The pretreatment values in Fig. 1 represent pooled values for groups 3 and 4 . The dogs were studied for up to $4 \mathrm{~h}$ from the time treatment with either DCA or $\mathrm{NaHCO}_{3}$ was begun. The 4-h mortality was $91 \%$ in 11 group 3 dogs treated with $\mathrm{NaHCO}_{3}$, while the mortality was $22 \%$ in 9 dogs receiving DCA. The cardiac indexes in the two groups of animals are shown in Fig. 2. During treatment with $\mathrm{NaHCO}_{3}$, mean cardiac index decline from $62.4 \pm 10.4 \mathrm{ml} / \mathrm{kg}$ per min to $26.4 \pm 14.9$ $\mathrm{ml} / \mathrm{kg}$ per min in $3 \mathrm{~h}(P<0.01)$. In the nine DCAtreated animals (group 4), cardiac index steadily rose from $68.6 \pm 7.0 \mathrm{ml} / \mathrm{kg}$ per min to $95.5 \pm 13.2 \mathrm{ml} / \mathrm{kg}$ per $\mathrm{min}$ after $4 \mathrm{~h}$ (control $=112 \pm 8.7 \mathrm{ml} / \mathrm{kg}$ per min, NS).

As shown in Fig. 1 and Table $I$, the changes in cardiac index were accompanied by corresponding changes in arterial $\mathrm{pH}$, bicarbonate, and lactate. There was no change in arterial $\mathrm{pH}$ in bicarbonate-treated dogs, but a significant rise occurred (from 7.08 to 7.29 , $P<0.01)$ in DCA-treated dogs. Similarly, blood bicarbonate was unaltered in bicarbonate-treated animals, but there was a significant increment (from 9.7 to $14.1 \mathrm{mM}, P<0.01$ ) in DCA-treated dogs. The arterial $\mathrm{pCO}_{2}$ was $32 \pm 3 \mathrm{~mm} \mathrm{Hg}$ in group 4 dogs, and after DCA it was unaltered $(32 \pm 3 \mathrm{~mm} \mathrm{Hg})$. However, in group 3 animals, arterial $\mathrm{pCO}_{2}$ rose from $30 \pm 1 \mathrm{~mm}$ $\mathrm{Hg}$ to $35 \pm 3 \mathrm{~mm} \mathrm{Hg}(P<0.01$ by paired $t$ test $)$. A more substantial change was observed in mixed venous (inferior vena cava) $\mathrm{pCO}_{2}$. Venous $\mathrm{pCO}_{2}$ was unaltered $(37 \pm 3 \mathrm{~mm} \mathrm{Hg})$ after DCA treatment but after bicarbonate therapy, it rose to $55 \pm 5 \mathrm{~mm} \mathrm{Hg}(P<0.001)$. The most dramatic changes in arterial blood were seen in the lactate values. After $\mathrm{NaHCO}_{3}$ therapy, blood lactate almost doubled (from 8.6 to $13.6 \mathrm{mM}, P$ $<0.01$ ). By contrast, DCA treatment resulted in a significant decrement of lactate (from 8.6 to $5.2 \mathrm{mM}, P$ $<0.01$, Fig. 1). The liver $\mathrm{pHi}$, which was significantly decreased in dogs with lactic acidosis, fell still further (from 6.81 to $6.71, P<0.01$ ) following $\mathrm{NaHCO}_{3}($ Table I). However, after DCA, there was an increment of hepatocellular pHi (to 6.90) such that the value was significantly greater $(P<0.01)$ than in $\mathrm{NaHCO}_{3}-$ treated dogs.

Thus, DCA therapy resulted in normalization of cardiac index, with improvement in arterial $\mathrm{pH}$, bicarbonate, lactate, and liver $\mathrm{pHi}$, whereas bicarbonate 
TABLE I

Effects of DCA vs. $\mathrm{NaHCO}_{3}$ in Dogs with Phenformin-Lactic Acidosis

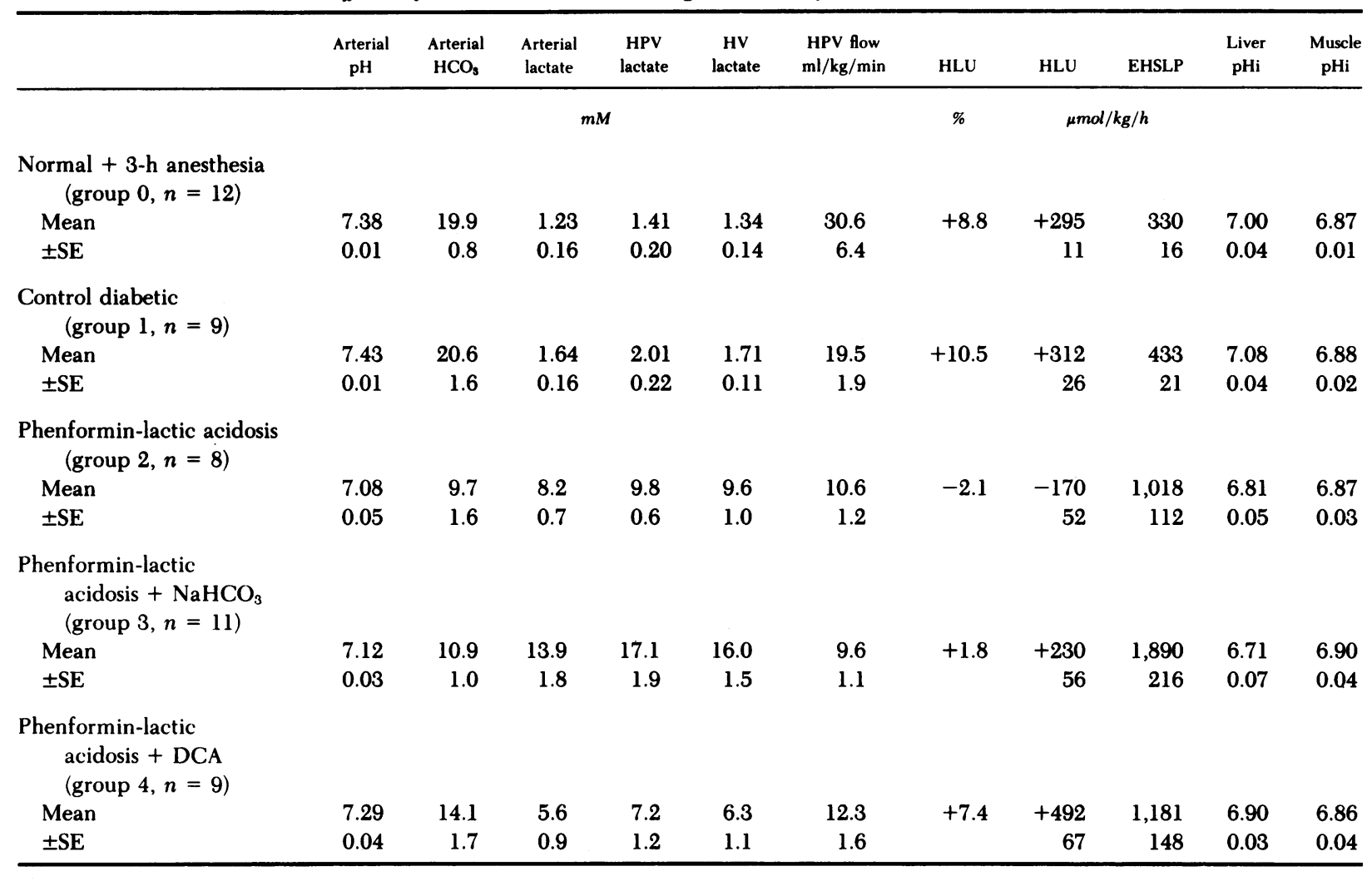

HLU, hepatic lactate uptake; EHSLP, extrahepatic splanchnic lactate production; HPV flow is in $\mathrm{ml} / \mathrm{kg}$ per $\mathrm{min}$.

therapy was associated with a decrement of cardiac output and liver $\mathrm{pHi}$, an increase in both arterial $\mathrm{pCO}_{2}$ and lactate, and venous $\mathrm{pCO}_{2}$, with no change in blood $\mathrm{pH}$ or bicarbonate. The mean survival time for DCAtreated animals (group 4) was $212 \pm 21 \mathrm{~min}$, while that in bicarbonate-treated dogs was $132 \pm 31 \mathrm{~min}(P$ $<0.01$ ). The survival times are calculated from the initiation of therapy. Survival times $>4 \mathrm{~h}$ were counted as $4 \mathrm{~h}$. Three dogs in group 4 were evaluated for extended survival after $4 \mathrm{~h}$ of DCA therapy. These three dogs had their laparotomy incision closed and were observed overnight. All three were alert and ambulatory the next day. The dogs were then sacrificed without additional studies being done.

Dogs with hepatectomy-lactic acidosis. Lactic acidosis was induced by functional hepatectomy, and dogs were treated with either $\mathrm{NaCl}, \mathrm{DCA}$, and $\mathrm{NaHCO}_{3}$. In 10 untreated dogs (group 5) with hepatectomy-lactic acidosis, arterial $\mathrm{pH}$ was $7.05 \pm 0.04$ (control $=7.38 \pm 0.01, P<0.01$ ) after $3 \mathrm{~h}$ of hepatectomy. The arterial lactate and bicarbonate were $9.1 \pm 0.9$ and $8.3 \pm 1.1 \mathrm{mM}$, respectively. Mean arterial pressure was $76 \pm 6 \mathrm{~mm} \mathrm{Hg}$ (control $=94 \pm 10 \mathrm{~mm} \mathrm{Hg}$ ), and cardiac index was $52.4 \pm 22.2 \mathrm{ml} / \mathrm{min}$ (control $=115 \pm 7.8 \mathrm{ml} / \mathrm{min}, P<0.01)$.

The controls for group 7 (pretreatment with DCA) were pretreated with $154 \mathrm{mM} \mathrm{NaCl}$ (group 6) so that volume status in the two groups was identical. After $3 \mathrm{~h}$, the arterial $\mathrm{pH}$, lactate, and bicarbonate in group 6 were $7.06 \pm 0.04,10.6 \pm 2.2 \mathrm{mM}$, and $7.6 \pm 0.6 \mathrm{mM}$, respectively (Fig. 3). Mean arterial pressure was $79 \pm 1$ $\mathrm{mm} \mathrm{Hg}$. After $4 \mathrm{~h}$, arterial pH was $6.89 \pm 0.05$, bicarbonate was $5.1 \pm 0.7 \mathrm{mM}$, and lactate was $11.7 \pm 2.6 \mathrm{mM}$. Four of six dogs survived $4 \mathrm{~h}$ after hepatectomy was performed.

Dogs in group 7 were pretreated with DCA (300 $\mathrm{mg} / \mathrm{kg}$ i.v. sustained infusion) and observed for up to $4 \mathrm{~h}$. After $3 \mathrm{~h}$, arterial lactate was $3.8 \pm 0.5 \mathrm{mM}$ while bicarbonate and $\mathrm{pH}$ were $11.4 \pm 1.3 \mathrm{mM}$ and $7.18 \pm 0.04$ respectively (Fig. 3). Mean arterial pressure was $79 \pm 8$ $\mathrm{mm} \mathrm{Hg}$. All of the values were significantly different from both untreated dogs and saline-treated dogs (Fig. 3). After $4 \mathrm{~h}$ of DCA, arterial lactate was $4.3 \pm 0.6 \mathrm{mM}$, arterial $\mathrm{pH}$ was $7.16 \pm 0.04$, and bicarbonate was 

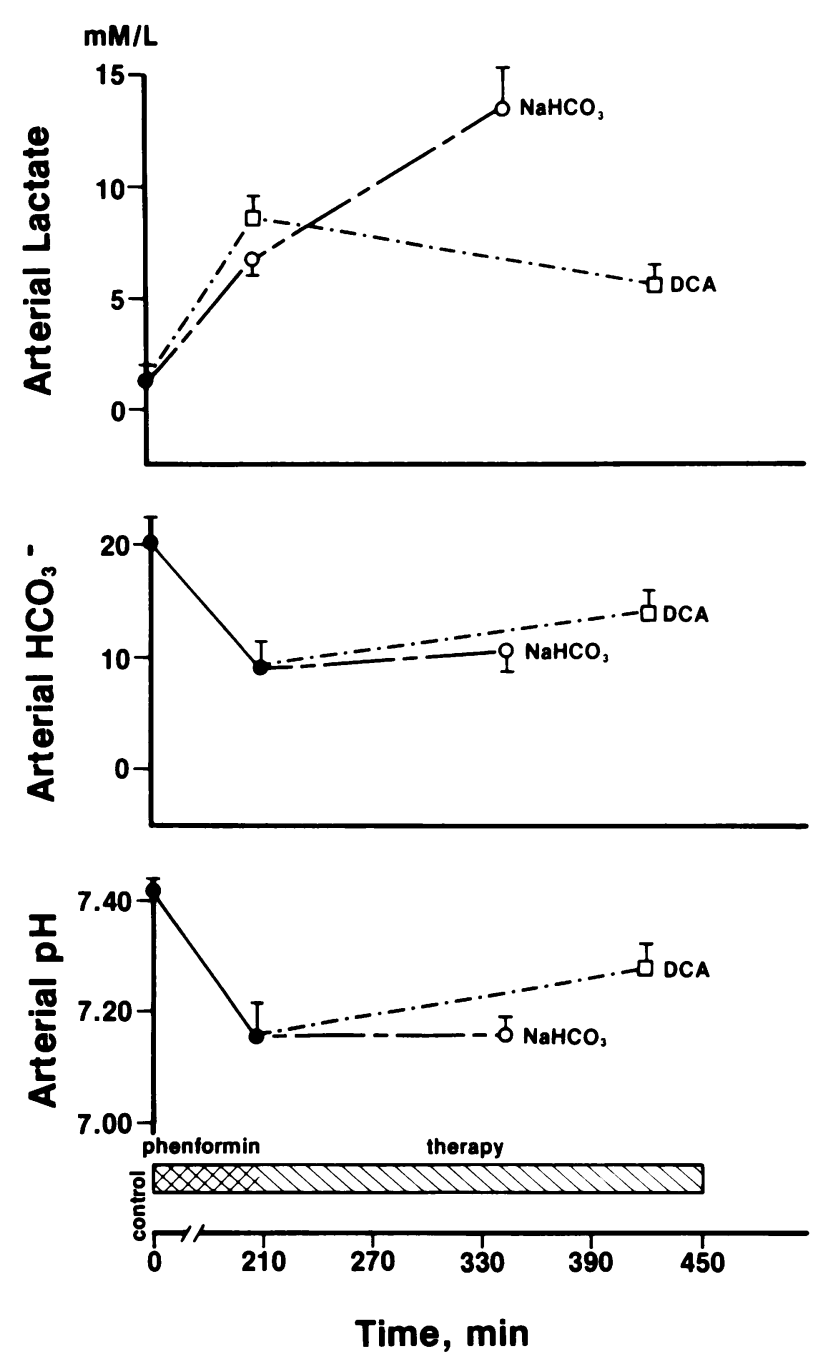

Figure 1 The effects of intravenous DCA vs. $\mathrm{NaHCO}_{3}$ in dogs with phenformin-lactic acidosis are compared. Two groups of diabetic dogs were given intravenous phenformin for a mean of $210 \mathrm{~min}$ (groups 3 and 4 ) and then half received DCA (group 4) while the other half was given $\mathrm{NaHCO}_{3}$ (group 3) for a maximum of $240 \mathrm{~min}$. In the DCAtreated animals arterial lactate was significantly lower $(P<0.01)$ while arterial $\mathrm{pH}$ and bicarbonate $\left(\mathrm{HCO}_{3}^{-}\right)$were significantly higher $(P<0.01)$, despite the fact that the bicarbonate-treated dogs had received an average of $72 \mathrm{meq}$ of $\mathrm{NaHCO}_{3}$, vs. none for the DCA-treated animals.

$11.0 \pm 1.1 \mathrm{mM}$ (Fig. 4). All six dogs treated with DCA survived $4 \mathrm{~h}$, at which time mean arterial pressure was $68 \pm 6 \mathrm{~mm} \mathrm{Hg}$.

In a separate group of dogs with hepatectomy-lactic acidosis, effects of DCA vs. $\mathrm{NaHCO}_{3}$ therapy were evaluated on cardiac index only (groups $8 \mathrm{a}$ and $8 \mathrm{~b}$ ). After $2.5 \mathrm{~h}$ of hepatectomy-lactic acidosis, arterial $\mathrm{pH}$ was $7.06 \pm 0.05$ and lactate was $10.1 \pm 1.1 \mathrm{mM}$. Cardiac index had fallen to $52.4 \mathrm{ml} / \mathrm{kg}$ per min vs. the control value of $115 \mathrm{ml} / \mathrm{kg}$ per $\min (P<0.01)$ (Fig. 4). At this point, half of the dogs were given $\mathrm{NaHCO}_{3}$ and half were given DCA. Experiments were terminated when mean arterial pressure fell below $50 \mathrm{~mm} \mathrm{Hg}$ or at the end of $4 \mathrm{~h}$ if the dogs survived.

Among dogs treated with $\mathrm{NaHCO}_{3}$, the cardiac index fell from 53.6 to $26.0 \mathrm{ml} / \mathrm{kg}$ per min during therapy (Fig. 4) and only two of the six bicarbonate-treated dogs survived $4 \mathrm{~h}$. The mean survival time was $147 \pm 37$ $\min$. At the time experiments were terminated, arterial $\mathrm{pH}$ was $7.34 \pm 0.04$ and lactate was $11.1 \pm 1.4 \mathrm{mM}$.

Among dogs treated with DCA, the mean survival time was $220 \pm 20 \mathrm{~min}$ significantly longer than the time in $\mathrm{NaHCO}_{3}$-treated dogs $(P<0.05)$ and five of six survived $4 \mathrm{~h}$. However, in contrast to the results in bicarbonate-treated dogs, cardiac index did not decline during DCA therapy (Fig. 4). The blood lactate in DCA-treated dogs was $6.4 \pm 1.2 \mathrm{mM}$, significantly less $(P<0.01)$ than the value in $\mathrm{NaHCO}_{3}$-treated animals. Arterial $\mathrm{pH}$ was $7.21 \pm 0.04$, a value not significantly different from that in $\mathrm{NaHCO}_{3}$ treated dogs $(P=0.07)$.

\section{DISCUSSION}

These data demonstrate that in dogs with two different types of type B experimental lactic acidosis, treatment with DCA significantly improves survival when compared with conventional therapy with either $\mathrm{NaCl}$ or $\mathrm{NaHCO}_{3}$. In addition to improved survival, therapy with DCA results in significant improvement of several biochemical and physiological entities. In particular, treatment with DCA results in either an increase (Fig. 2) or stabilization (Fig. 4) of cardiac output; a decrement of blood lactate and an increase of blood $\mathrm{pH}$ and bicarbonate (Fig. 1); and a rise in liver $\mathrm{pHi}$ (Table I).

In normal fasted dogs, DCA does not appear to increase lactate uptake by the liver (20). However, we evaluated the effects of DCA in dogs with phenforminlactate acidosis, where fractional hepatic lactate extraction was actually negative $(-2.1 \%$ vs. control value of $7.4 \%$ ). Following treatment, absolute hepatic lactate uptake was twice the value in DCA vs. $\mathrm{NaHCO}_{3}-$ treated animals (492 vs. $230 \mu \mathrm{mol} / \mathrm{kg}$ per h, Table I). In terms of fractional removal of lactate, DCA-treated dogs extracted $7.4 \%$ of the calculated lactate load presented to the liver $(492$ of $6,691 \mu \mathrm{mol} / \mathrm{kg}$ per h) vs. only $1.8 \%$ of the total ( 230 of $12,518 \mu \mathrm{mol} / \mathrm{kg}$ per $\mathrm{h}$ ) removed in $\mathrm{NaHCO}_{3}$-treated dogs. Thus, the effects of DCA on blood lactate appear to be mediated in part by increased removal by the liver. The fractional he- 


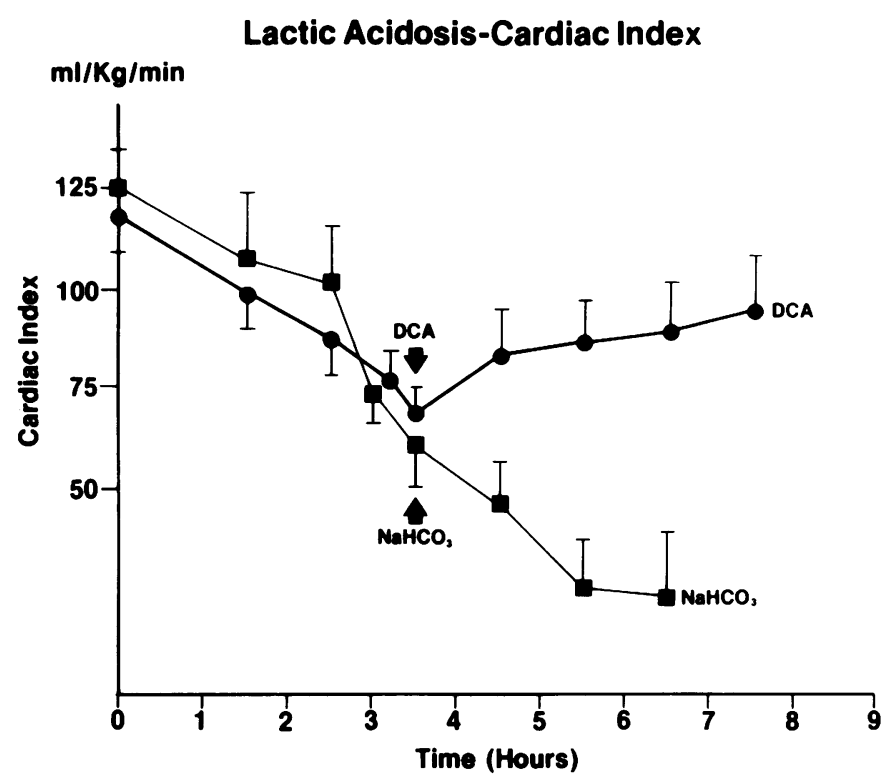

Figure 2 The effects of $\mathrm{NaHCO}_{3}$ vs. DCA treatment on cardiac index in dogs with phenforminlactic acidosis. After $4 \mathrm{~h}$ of intravenous DCA, cardiac index is not significantly different from the control value. During treatment with $\mathrm{NaHCO}_{3}$, cardiac index progressively diminished, leading to an eventual $91 \%$ mortality, vs. a $22 \%$ mortality in DCA-treated dogs.

patic lactate extraction in diabetic dogs with phenformin-lactic acidosis receiving DCA (7.4\%) was similar to the control diabetic value $(10.5 \%)$ but less than the fractional extraction previously reported in fasted dogs treated with DCA infusion (20\%) (20).

In dogs with hepatectomy-lactic acidosis, pretreatment with DCA resulted in a significantly lower blood lactate than did pretreatment with $\mathrm{NaCl}$ (Fig. 4). Since the liver was not present in this preparation, the observed effect of DCA on blood lactate had to be due to a decrease in extrahepatic lactate production.

There was no observed effect of DCA on gut production of lactate (extrahepatic splanchnic lactate production, Table I). Gut production of lactate in dogs with phenformin-lactic acidosis was $1,018 \mu \mathrm{mol} / \mathrm{kg}$ per $\mathrm{h}$ (control $=433 \mu \mathrm{mol} / \mathrm{kg}$ per $\mathrm{h}, P<0.01$ ) and this value was unaffected by DCA (Table I). Effects of DCA on gut lactate production have not previously been evaluated in lactic acidosis, but studies in normal fasting dogs have also shown that DCA has no effect (20).

Liver pHi, which is decreased in dogs with phenformin-lactic acidosis, was significantly increased by DCA, and lowered by $\mathrm{NaHCO}_{3}$ (Table I). It has been shown that under a variety of physiological conditions that encompass an extracellular $\mathrm{pH}(\mathrm{pHe})$ range of 7.66-7.09, hepatic pHi does not change (16). In animals with phenformin-lactic acidosis, both in vivo $(\mathrm{dog})$ and in vitro (isolated perfused guinea pig liver), hepatic pHi is decreased $(14,21)$. The fall in pHi may have any of several possible important functional consequences.

One of the major substrates for hepatic gluconeogenesis is lactate. One of the rate-limiting enzymes for glucose synthesis from lactate is pyruvate carboxylase (22). This enzyme catalyzes the conversion of pyruvate to oxaloacetate and is markedly $\mathrm{pH}$ sensitive. At $\mathbf{p H}$ below $\sim 6.90$, both enzyme activation and reaction velocity fall markedly (22-24). In this study, hepatic pHi was 6.81 (control $=7.08, P<0.01$ ) and this was associated with marked impairment in liver lactate uptake. It is possible that impaired activity of pyruvate carboxylase was a factor in the decreased liver lactate uptake.

The lactate load presented to the liver in dogs with phenformin-lactic acidosis was $7,952 \mu \mathrm{mol} / \mathrm{kg}$ per $\mathrm{h}$, but hepatic uptake was actually negative $(-170 \mu \mathrm{mol} /$ $\mathrm{kg}$ per $\mathrm{h}$, Table I). We have previously shown that the normal dog liver can extract at least $19 \%$ of the lactate load presented (2.3 of $12.2 \mathrm{mmol} / \mathrm{kg}$ per h), (16) and data from other laboratories are similar (20). DCA resulted in an increment of liver pHi to 6.90. Liver lactate extraction after DCA infusion increased from $-2.1 \%$ to $7.4 \%$ of the delivered load, whereas with $\mathrm{NaHCO}_{3}$ administration, extraction was only $1.8 \%$. The rate of volume expansion was identical in the two groups. It may be that the increased lactate uptake following DCA was at least in part responsible for the 
increment in hepatocellular pHi. Cohen and associates $(24,25)$ have presented evidence that for each lactate metabolized by the liver a proton is consumed, resulting in generation of a base equivalent that results in an increment of liver pHi. There may also be a direct action of DCA on liver pHi. Such an effect has not previously been evaluated and the present study provides no additional specific data. However, DCA also has a number of additional effects on the liver, both in vivo and in vitro, many of which appear unrelated to pyruvate dehydrogenase activation (26). The effects include amino acid transamination, production of oxalate and glyoxylate, and stimulation of fatty acid synthesis (26). These or other actions may in part explain the effect of DCA on liver pHi.

In comparing the effects of therapy with DCA vs. $\mathrm{NaHCO}_{3}$, it should be pointed out that we were not able to normalize arterial pH with $\mathrm{NaHCO}_{3}$ (Fig. 2). It may be that if arterial $\mathrm{pH}$ had been normalized, the effects on lactic acidosis might have been different. In reviewing the literature, one sees that it has been possible to normalize arterial $\mathrm{pH}$ with $\mathrm{NaHCO}_{3}$ in some individuals with lactic acidosis but not in others (2, 27-30). In 102 patients with phenformin-lactic acidosis, infusion of a mean of 527 meq of $\mathrm{NaHCO}_{3}$ normalized arterial $\mathrm{pH}$ in $66 \%$ of patients (28). However, infusion of 500-1,200 meq/d of $\mathrm{NaHCO}_{3}$ had no effect on arterial $\mathrm{pH}$ in five patients with other forms of lactic acidosis $(2,29,30)$. Our dogs were potentially different from patients with lactic acidosis in several respects. In patients, the acidosis is of ten more severe (28), the patients are usually able to hyperventilate and to lower arterial $\mathrm{pCO}_{2}$ (ventilation is fixed to maintain a constant arterial $\mathrm{pCO}_{2}$ in the dogs), and it is often possible to normalize arterial $\mathrm{pH}$ with $\mathrm{NaHCO}_{3}$ (28). Thus, it may not be possible to draw conclusions about the relative efficacy of DCA vs. effective alkalinization. However, it must be pointed out that the quantity of bicarbonate infused $(2.5 \mathrm{meq} / \mathrm{kg}$ per $\mathrm{h})$ would be the equivalent of infusing $3,600 \mathrm{meq} / \mathrm{d}$ to a $60-\mathrm{kg}$ human. Such a quantity of $\mathrm{NaHCO}_{3}$ would raise serum sodium to $>200 \mathrm{meq} / \mathrm{liter}$, a condition which in itself carries a mortality $>80 \%$ (31). In addition, infusion of bicarbonate resulted in production by the gut of an almost stoichiometric quantity of lactic acid (6). Thus, in this animal model, as well as in several reported cases, effective alkalinization was not possible $(2,27,29,30)$. The most important factor in determining survival in patients with lactic acidosis may well be the presence of shock. With either clinical shock or arterial $\mathrm{pH}<6.9$, mortality from phenforminlactic acidosis is $>70 \%(27,28)$.

The effects of DCA on cardiac index were among the most important results observed in the current

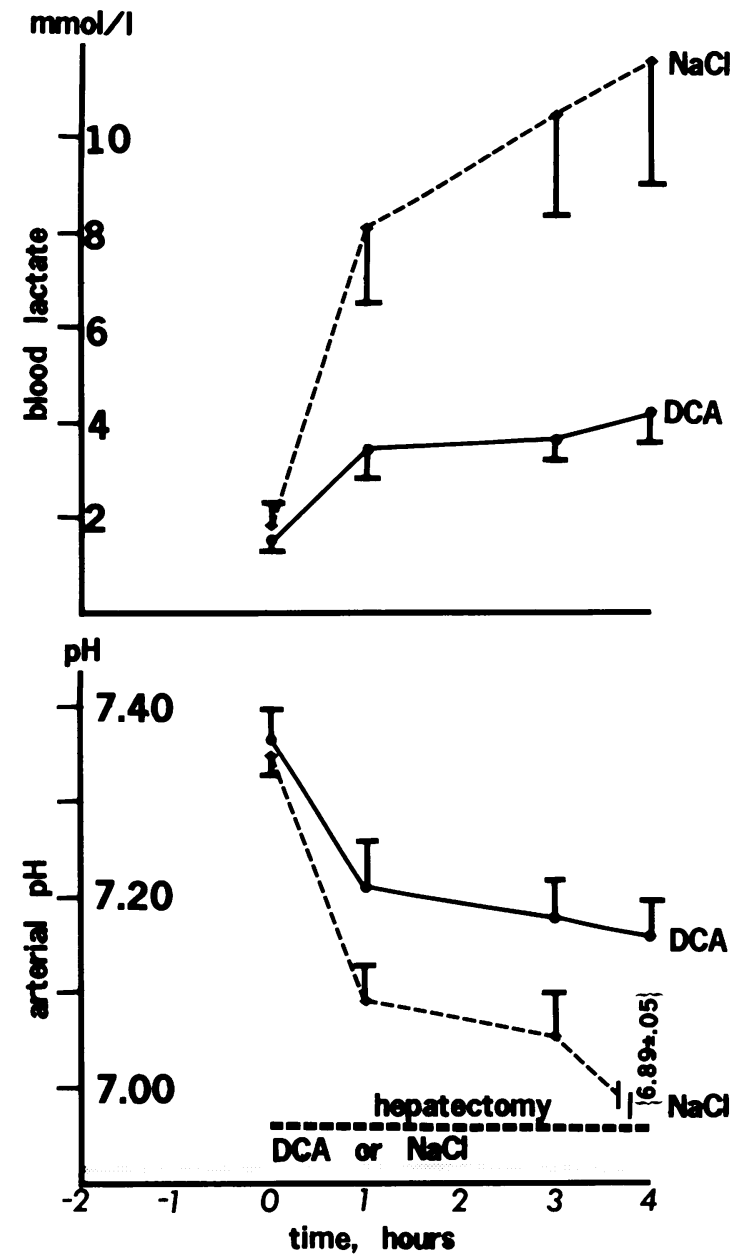

FIgURE 3 Two groups of dogs with hepatectomy-lactic acidosis (groups 6 and 7) were pretreated with either $\mathrm{NaCl}$ or DCA for $2 \mathrm{~h}$ before hepatectomy. The animals continued to receive either $\mathrm{NaCl}$ or DCA for the duration of hepatectomy, and arterial $\mathrm{pH}$ and lactate were compared in the two groups. At intervals of $1,2,3$, and $4 \mathrm{~h}$, arterial $\mathrm{pH}$ was significantly greater $(P<0.01)$ and lactate significantly less $(P$ $<0.01)$ in DCA-treated dogs vs. those treated with $\mathrm{NaCl}$.

study (Figs. 2 and 4). In dogs with phenformin-lactic acidosis, we have previously shown that cardiac index is significantly decreased $(6,15)$. The low cardiac index is not a result of metabolic acidemia $(15,32)$ and is not restored by volume expansion with $\mathrm{NaCl}$ or by $\mathrm{NaHCO}_{3}$ infusion. The low cardiac index may be due to a low cardiac pHi (33). In addition, $\mathrm{NaHCO}_{3}$ infusion further decreased cardiac index (Fig. 2). Bicarbonate has been shown to lower pHi, both in vitro and in vivo under selected conditions $(6,28)$. The $\mathrm{NaHCO}_{3}$ infusion may have elevated blood $\mathrm{pCO}_{2}$, leading to a decrement of heart pHi $(33,34)$. Such an 


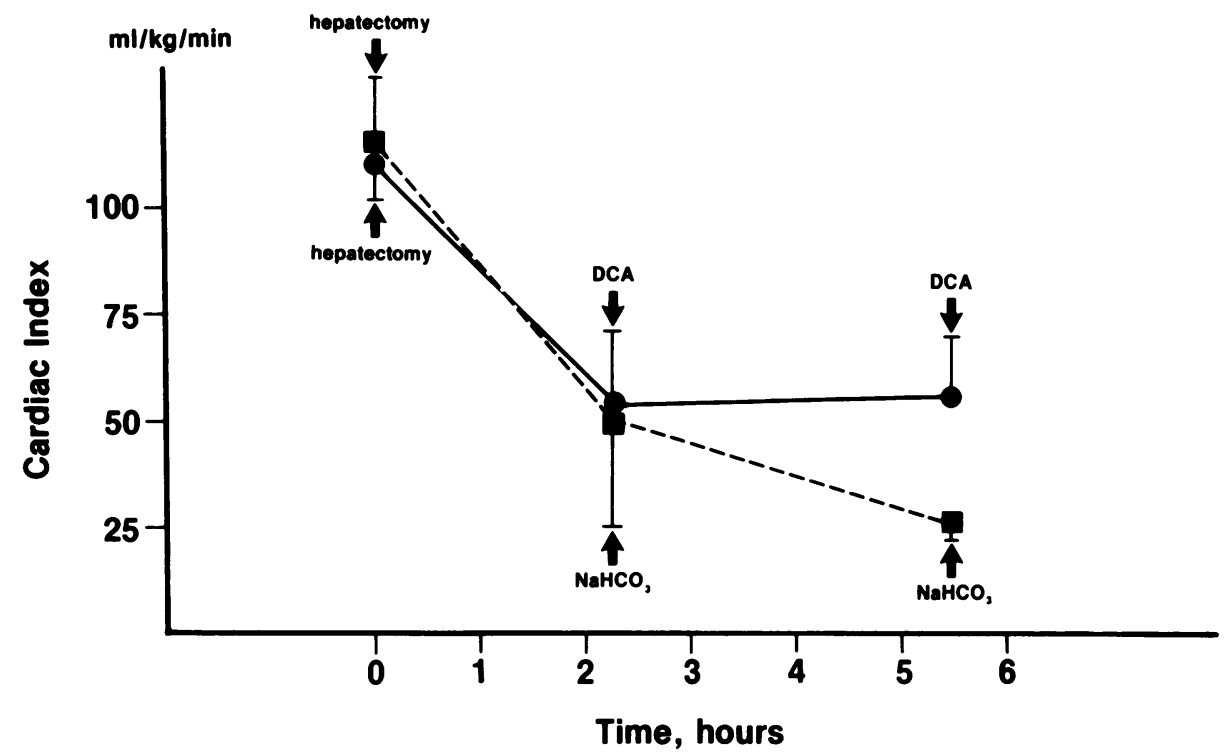

FigUre 4 The effects on cardiac index of therapy with DCA vs. $\mathrm{NaHCO}_{3}$ in dogs with hepatectomy-lactic acidosis. After $135 \mathrm{~min}$ of functional hepatectomy, cardiac index was reduced to $46 \%$ of the control value. In dogs treated with DCA, there was no further change in cardiac index, while in $\mathrm{NaHCO}_{3}$-treated animals cardiac index continues to deteriorate. The 4-h survival was $83 \%$ in DCA-treated dogs vs $33 \%$ in those treated with $\mathrm{NaHCO}_{3}$.

effect could be expected to further depress myocardial contractility (33). In fact, although myocardial pHi was not evaluated, mixed venous $\mathrm{pCO}_{2}$ did increase from $37 \pm 3$ to $55 \pm 5 \mathrm{~mm} \mathrm{Hg}$ after $\mathrm{NaHCO}_{3}$ infusion $(P<0.001)$.

After $4 \mathrm{~h}$ of DCA infusion, cardiac index was not significantly different from control values (Fig. 2). The reasons for improvement in cardiac function following DCA are unclear. Studies by McAllister and associates (11) in dogs showed that DCA increased lactate extraction by the heart whereas previous studies have demonstrated that myocardial extraction of both lactate and oxygen are impaired in dogs with phenformin-lactic acidosis (15). Furthermore, such dogs develop electrocardiogram abnormalities compatible with an acute ischemic injury current (15). In another model of acute myocardial ischemic injury, Mjos and associates (35) have evaluated effects of DCA infusion. In dogs with experimental coronary artery occlusion, intravenous DCA reduced the degree of ST-segment elevation, concomittant with increased myocardial extraction of glucose and decreased FFA extraction. These effects of DCA in the ischemic heart may also be operative in dogs with phenformin-lactic acidosis or hepatectomy-lactic acidosis.

We have also previously shown that in dogs with hepatectomy-lactic acidosis, cardiac index gradually decreases, and that this functional deterioration is not due to metabolic acidemia per se (15). Others have documented cardiovascular collapse in liver failure, both in patients (36) and hepatectomized dogs (37). DCA administered to dogs with hepatectomy-lactic acidosis prevented further deterioration of cardiac index (Fig. 4). Pretreatment with DCA in dogs who subsequently underwent hepatectomy resulted in significantly improved survival, as well as lower blood lactate with higher arterial pH (Fig. 3).

Thus, DCA administration is associated with either biochemical, electrocardiographic or functional improvement of the heart in dogs with any of three different causes of myocardial deterioration: hepatectomy lactic acidosis (Fig. 4); phenformin-lactic acidosis (Table I, Fig. 2); or coronary artery occlusion (35). The relationship between these findings and known effects of DCA on the heart is not yet established $(11,26,33)$.

Data from the present study (Figs. 1 and 3 ) and previous investigations $(7-10,20,36,38)$ show that intravenous DCA infusion can lower blood lactate levels under a variety of circumstances. In lactic acidosis due to either hepatectomy or phenformin, DCA infusion also results in improvement of blood $\mathrm{pH}$ and bicarbonate and an increase or stabilization of cardiac index (Figs. 1-4). The aforementioned effects of DCA are also associated with significantly improved 4-h survival in both phenformin-lactic acidosis ( $78 \%$ survival 
with DCA vs. 9\% survival with $\mathrm{NaHCO}_{3}$ treatment) and hepatectomy-lactic acidosis (92\% survival with DCA vs. $50 \%$ combined survival with $\mathrm{NaCl}$ or $\mathrm{NaHCO}_{3}$ ). These effects of DCA may be unique to only these two forms of lactic acidosis and it is possible that DCA would be ineffectual in other forms of lactic acidosis. Additionally, as has been suggested (39), DCA may lower blood lactate in some forms of lactic acidosis but have no effect on the course of the associated illness (38).

There are some toxic effects of DCA that have been described after chronic administration. There include limb paralysis, cataracts, increased urinary oxalate excretion, testicular degeneration, neuropathy, mutagenicity, and changes in central nervous system white matter (26). Most such toxic effects result from long term oral administration of DCA, with few if any side effects reported with short-term intravenous use (26). Short-term administration to human subjects orally or intravenously has not resulted in any serious side effects $(9,38,40)$. With the aforementioned reservations in mind, clinical trials of DCA as adjunctive therapy of lactic acidosis are probably indicated (13).

\section{ACKNOWLEDGMENTS}

The authors thank Mr. David Burlew for excellent secretarial and administrative assistance.

This study was supported by a grant from the Kroc Foundation, Santa Ynez, CA, a grant from the National Institute of Arthritis, Metabolism, and Digestive Diseases, National Institutes of Health (ROl AM18350) and by the Research Service of the Veterans Administration.

\section{REFERENCES}

1. Oliva, P. B., 1970. Lactic acidosis. Am. J. Med. 48: 209225.

2. Waters, W. C. III, J. D. Hall, and W. B. Schwartz. 1963. Spontaneous lactic acidosis. Am. J. Med. 35: 781-793.

3. Cohen, R. D., and H. F. Woods. 1976. Clinical and Biochemical Aspects of Lactic Acidosis. Blackwell Scientific Publications, Oxford, England. 40-76.

4. Misbin, R. I. 1977. Phenformin-associated lactic acidosis: pathogenesis and treatment. Ann. Intern. Med. 87: 591595.

5. Park, R., and A. I. Arieff. 1980. Lactic acidosis. Adv. Intern. Med. 25: 33-68.

6. Arieff, A. I., R. Park, W. Leach, and V. C. Lazarowitz. 1982. Systemic effects of $\mathrm{NaHCO}_{3}$ in experimental lactic acidosis in dogs. Am. J. Physiol. 242: F586-F591.

7. Blackshear, P. J., P. A. H. Holloway, and K. G. M. Alberti. 1974. The metabolic effects of sodium dichloroacetate in the starved rat. Biochem. J. 142: 279-286.

8. Loubatieres, A. L., G. Ribes, and G. Valette. 1976. Pharmacological agents and acute experimental hyperlactatemia in the dog. Br. J. Pharmacol. 58: 429P.

9. Stacpoole, P. W., G. W. Moore, and D. M. Kornhauser. 1978. Metabolic effects of dichloroacetate in patients with diabetes millitus and hyperlipoproteinemia. $N$. Engl. J. Med. 298: 526-530.

10. Merrill, G. F., E. J. Zambraski, and S. M. Grassl. 1980. Effect of dichloroacetate on plasma lactic acid in exercising dogs. J. Appl. Physiol. Resp. Environ. Exercise Physiol. 48: 427-431.

11. McAllister, A., S. P. Allison, and R. J. Randle. 1973. Effects of dichloroacetate on the metabolism of glucose, pyruvate, acetate, 3-hydroxybutyrate, and palmitate in rat diaphragm and heart muscle in vitro and on extraction of glucose, lactate, pyruvate, and free fatty acids by dog heart in vivo. Biochem. J. 134: 1067-1081.

12. Whitehouse, S., R. H. Cooper, and P. J. Randle. 1974. Mechanism of action of pyruvate dehydrogenase by dichloroacetate and other halogenated carboxylic acids. Biochem. J. 141: 761-774.

13. Relman, A. D. 1978. Lactic acidosis and a possible new treatment. N. Engl. J. Med. 298: 564-566.

14. Arieff, A. I., R. Park, W. J. Leach, and V. C. Lazarowitz. 1980. Pathophysiology of experimental lactic acidosis in dogs. Am. J. Physiol. 239: F135-F142.

15. Arieff, A. I., E. D. Gertz, R. Park, W. Leach, and V. C. Lazarowitz. 1982. Lactic acidosis and the cardiovascular system in the dog. Clin. Sci. (Oxf.). In press.

16. Park, R., W. J. Leach, and A. I. Arieff. 1979. Determination of the liver intracellular $\mathrm{pH}$ in vivo and its homeostasis in acute acidosis and alkalosis. Am. J. Physiol. 236: F240-F245.

17. Park, R., W. J. Leach, and A. I. Arieff. 1980. Measurement of the liver extracellular space in vivo in dogs. Horm. Metab. Res. 12: 680-684.

18. Greenway, C. V., and R. D. Stark. 1971. Hepatic vascular bed: Hepatic flows. Physiol. Rev. 51: 26-29.

19. Park, R., W. J. Leach, and A. I. Arieff. 1979. Dichloroacetate decreases extrahepatic lactate production in diabetic dogs. Clin. Res. 27: 374a.

20. Diamond, M. P., R. C. Rollings, L. Erlendson, P. E. Williams, W. W. Lacy, D. Rabin, and A. D. Cherrington. 1980. Dichloroacetate-its in vivo effects on carbohydrate metabolism in the conscious dog. Diabetes. 29: 702-709.

21. Lloyd, M. H., R. A. Iles, B. Walton, C. A. Hamilton, and R. D. Cohen. 1975. Effect of phenformin on gluconeogenesis from lactate and intracellular $\mathrm{pH}$ in the isolated perfused guinea pig liver. Diabetes. 24: 618-624.

22. Scutton, M. D., and M. F. Utter. 1967. Pyruvate carboxylase: Some properties of the activation by certain acyl derivatives of coenzyme A. J. Biol. Chem. 242: 1723-1735.

23. Relman, A. S. 1972. Metabolic consequences of acid-base disorders. Kidney Int. 1: 347-359.

24. Cohen, R. D., R. A. Iles, D. Barnett, M. E. O. Howell, and J. Strunin. 1971. The effect of changes in lactate uptake on the intracellular $\mathrm{pH}$ of the perfused rat liver. Clin. Sci. (Oxf.). 41: 159-170.

25. Baron, P. G., R. A. Iles, and R. D. Cohen. 1978. Effect of varying $\mathrm{pCO}_{2}$ on intracellular $\mathrm{pH}$ and lactate consumption in the isolated perfused rat liver. Clin. Sci. Mol. Med. 55: 175-181.

26. Crabb, D. W., E. A. Yount, and R. A. Harris. 1981. The metabolic effects of dichloroacetate. Metab. Clin. Exp. 30: 1024-1039.

27. Fulop, M., and H. D. Hoberman. 1976. Phenformin-associated metabolic acidosis. Diabetes. 25: 292-296.

28. Luft, D., R. M. Schmulling, and M. Eggstein. 1978. Lac- 
tic acidosis in biguanide-treated diabetics. Diabetologia 14: 75-87.

29. Fraley, D. S., S. Adler, F. J. Bruns, and B. Zett. 1980. Stimulation of lactate production by administration of bicarbonate in a patient with a solid neoplasm and lactic acidosis. N. Engl. J. Med. 303: 1100-1102.

30. Fields, A. L. A., S. L. Wolman, and M. L. Halperin 1981. Chronic lactic acidosis in a patient with cancer therapy and metabolic consequences. Cancer (Phila.). 47: 2026-2029.

31. Covey, C. M., and A. I. Arieff. 1978. Disorders of sodium and water metabolism and their effects on the central nervous system. In Contemporary Issues in Nephrology Vol. I. B. M. Brenner and J. H. Stein, editors. Churchill Livingstone, New York. 212-241.

32. Downing, S. E., J. C. Lee, and J. C. Werner. 1981. Effects of insulin on ventricular function in diabetic lambs with acidosis. Am. J. Physiol. 24: H401-H407.

33. Steenbergen, C., G. Deleeuw, T. Rich, and J. R. Williamson. 1977. Effects of acidosis and ischemia on contractility and intracellular $\mathrm{pH}$ of rat heart. Circ. Res. 41: 849-858.

34. Cohen, R. D., B. R. Simpson, F. J. Goodwin, and L. Strunin. 1967. The early effects of infusion of sodium bicarbonate and sodium lactate on intracellular hydrogen ion activity in dogs. Clin. Sci. (Oxf.). 33: 233-247.

35. Mjos, O. D., N. E. Miller, R. A. Riemersma, and M. F. Oliver. 1976. Effects of dichloroacetate on myocardial substrate extraction, epicardial ST-segment elevation, and ventricular blood flow following coronary occlusion in dogs. Cardiovasc. Res. 10: 427-436.

36. Trewby, P. N., R. A. Chase, M. Davis, and R. Willaims. 1977. The role of the false neurotransmitter octopamine in the hypotension of fulminant hepatic failure. Clin. Sci. Mol. Med. 52: 305-310.

37. Mattson, W. J., and J. G. Turcotte. 1969. Survival and metabolism in experimental endogenous hepatic coma. Surg. Gynecol. Obstet. 128: 557-564.

38. Coude, F. X., J. M. Saudubray, F. DeMaugre, C. Marsac, and J. P. Leroux. 1978. Dichloroacetate as treatment for congenital lactic acidosis. N. Engl. J. Med. 299: 13651366.

39. Cohen, R. D., and R. A. Iles. 1978. Dichloroacetate and the treatment of lactic acidosis. N. Engl. J. Med. 298: 1364.

40. Wells, P. G., G. W. Moore, D. Rabkin, G. R. Wilkinson, J. A. Oates, and P. W. Stacpoole. 1980. Metabolic effects and pharmacokinetics of intravenously administered dichloroacetate in humans. Diabetologia. 19: 109-113. 